\title{
3 Research Square

\section{Impact of maternal age on birthweight in frozen embryo transfer cycles: an analysis including 12565 singleton newborns}

\section{Zhexin Ni}

Changhai Hospital

\section{Shuai Sun}

Changhai Hospital

\section{Wen Cheng}

Changhai Hospital

Jin Yu

Changhai Hospital

Dongxia Zhai

Changhai Hospital

Danying Zhang

Changhai Hospital

\section{Zailong Cai}

Navay Medical University

Yanping Kuang

Shanghai Ninth People's Hospital

Chaoqin Yu ( $\sim$ chqyu81@163.com)

Changhai Hospital, Shanghai https://orcid.org/0000-0003-1614-2655

\section{Research article}

Keywords: ART, frozen-thawed embryo transfer, vitrification, maternal age, birthweight

Posted Date: May 31st, 2020

DOl: https://doi.org/10.21203/rs.3.rs-28453/v1

License: (c) (1) This work is licensed under a Creative Commons Attribution 4.0 International License.

Read Full License 


\section{Abstract}

Background Previous studies have investigated the effect of maternal age on assisted reproductive technology (ART) success rates. However, little is known about the relationship between maternal age and neonatal birthweight in frozen embryo transfer (FET) cycles. Does maternal age have an impact on singleton birthweight in FET cycles?

Methods This retrospective study was conducted at a tertiary care centre, involving singleton live births born to women undergoing frozen-thawed embryo transfer during the period from January 2010 to December 2017. A total of 12565 women who fulfilled the inclusion criteria were enrolled and were grouped into four groups according to the maternal age: $<30,30-34,35-39$, and $\geq 40$ years old.

Maternal age between 30 and 34 years old was taken as a reference group. Singleton birthweight was the key outcome measure. A multivariable linear regression analysis was conducted to reveal the relationship between maternal age and neonatal birthweight with controlling for a number of potential confounders.

Results A modest decrease but no significant difference in birthweight and gestational age- and genderadjusted birthweight (Z-scores) was observed in maternal age over 35 years old as compared with group with 30-34 years old. Further, multiple linear regression analyses indicated that maternal body mass index (BMI), embryo developmental stage at transfer, parity, number of embryos transferred, FET endometrial preparation, endometrial thickness, gestational age and newborn gender were all independent predictors of neonatal birthweight.

Conclusion Grouping with different maternal age was not associated with mean birthweight and Z-scores of singletons resulting from FET.

\section{Background}

In the past decades, many women delay childbearing until after the age of 40 . The decline of fertility of elderly women forced them to seek the help of ART. According to statistics by European IVF-monitoring Consortium, the proportion of women over 40 years old pregnant through IVF/ICSI increased in Europe year by year. In the UK, for example, the proportion increased from 12.7-26\% during 1997 to 2015 , and the same trend was observed in other high-income countries $[1,2]$.

Having a healthy baby is the ultimate goal of ART treatment. Increased risk of adverse neonatal outcomes are believed to appear in in vitro fertilization or intracytoplasmic sperm injection (IVF/ICSI) conceived babies, even singletons, such as preterm birth (PTB), low birthweight (LBW) and small for gestational age (SGA), when compared with peers conceived spontaneously [3]. Maternal age is a frequently-used predictor of PTB, LBW, and perinatal mortality in women who have conceived naturally [4-7], and a number of studies have well revealed the negative correlation between maternal age and neonatal outcomes $[8,9]$. Women who have a baby through ART are, on average, older than women who conceive spontaneously, as these techniques are often applied in response to age-related infertility 
problems [10]. However, little is known regarding the influence of maternal age on birthweight in vitrifiedthawed blastocyst transfer cycles.

To our knowledge, only few studies have examined the effect of maternal age on birthweight with ART, containing different kinds of treatments without considering enough confounders [11-14]. Further, the published data, except for Lin's study [14], exclusively focused on fresh IVF cycles, without ruling out the possibility of adverse fetal growth caused by a hypoestrogenic milieu. Of note, supraphysiological estrogen levels during ovarian stimulation can create a suboptimal peri-implantation environment for implantation and placentation, thus causing abnormal fetal growth including LBW and SGA $[15,16]$. Unlike fresh ovarian stimulation cycles, FET seems to provide a more physiological uterine environment for early fetal development [17]. Thus, the current study aims to explore the effect of maternal age on the birthweight of newborns conceived by blastocyst transfers during FET cycles.

\section{Methods}

\section{Study design and patients}

This retrospective study involved women who had undergone FET during the period from January 2010 to December 2017, which was performed at the Department of Assisted Reproduction of the Ninth People's Hospital of Shanghai Jiao Tong University School of Medicine. Women who met the following inclusion criteria were involved in the study: $\mathrm{BMI}<30 \mathrm{~kg} / \mathrm{m}^{2}$, the transfer of blastocyst resulting in a live singleton birth.

The exclusion criteria were vanishing twin syndrome, congenital uterine malformations, and other diseases as determined by ultrasound or hysteroscopy. And exclude women with gestational diabetes, pregnancy-induced hypertension and preeclampsia, as these pregnancy-related factors may have bad effect on intrauterine fetal growth. Further, only the first pregnancy was retained for the women wo had more than one delivery during the study period. This study was approved by the Institutional Review Board of the hospital.

\section{Laboratory protocols}

The procedures of ovarian stimulation, oocyte retrieval and IVF/ICSI have been described in previous studies $[18,19]$. In brief, IVF or ICSI was conventionally carried out based on semen parameters and previous fertilization histories. For IVF, oocytes were inseminated in human tubal fluid (HTF; Irvine Scientific) with approximately 300000 progressively motile spermatozoa, and was supplemented with $10 \%(\mathrm{v} / \mathrm{v})$ serum substitute supplement (SSS; Irvine Scientific). For ICSI, oocytes were transferred into dishes immediately after microinjection with $\mathrm{HTF}+10 \% \mathrm{SSS}$. The assessment of fertilization was performed 16-18 h post insemination/injection. A dish containing preequilibrated culture medium was then prepared for the transfer of zygotes. In this study, blastocysts were cultured in early cleavage medium (Irvine Scientific) before Day 3 and then in multiblast medium (Irvine Scientific) before 2013. However, a continuous single culture medium (Irvine Scientific) was introduced after January 2013. 
All embryos were cultured under mineral oil and grew in the incubator at $37{ }^{\circ} \mathrm{C}$, under $5 \% \mathrm{O}_{2}$ and $6 \% \mathrm{CO}_{2}$ concentration (the balance gas was nitrogen). The assessement of embryo development was performed on Day 3, and only high-quality cleavage-stage embryos were selected for cryopreservation, which was at least six blastomeres with $\leq 20 \%$ fragmentation. Except for the change of culture media types, no change was made for the other laboratory conditions and IVF protocols throughout the study period.

\section{Endometrial preparation and vitrification}

Protocols of endometrial priming for FET have been previously described [20]. Briefly, a natural cycle FET was suitable for women having regular menstrual cycles with the use of hCG for triggering ovulation. Artificial cycles were offered for women with irregular cycles according to the discretion of treating physicians. The procedure of vitrification and thawing were previously described [19]. In short, Cryotop carrier system with dimethylsulfoxide-ethylene glycol-sucrose was used as cryoprotectants for embryo vitrification. Dilution solution in a sequential manner ( $1 \mathrm{~mol} / \mathrm{L}$ to $0.5 \mathrm{~mol} / \mathrm{L}$ to $0 \mathrm{~mol} / \mathrm{L}$ sucrose) was used for thawing of embryos. All embryos were thawed on the day of transfer.

\section{Maternal age}

Maternal age at the birth of the child was the key explanatory variable, which was divided into the following categories: $<30,30-34,35-39$, and $\geq 40$ years old. The age group $30-34$ years old was set as the reference category in our analyses, as most of the ART births were to women in this age group [13].

\section{Outcome measures}

The main neonatal outcomes was live singleton birthweight. The definition for live singleton birth was a delivery of a singleton viable infant after the 20th gestational week. Gestational age (GA) in FET cycles was calculated from the day of embryo transfer (Day 17 for cleavagestage embryo transfer) [21]. The definition for PTB and very PTB were delivery before 37 and 32 completed gestational weeks, respectively. Z-scores were calculated according to gestational age and newborn gender on birthweight based on the national birthweight reference as previously described [22,23]. Birthweight of infant was divided into the following categories: LBW (<2500 g), very LBW (<1500 g), high birthweight (HBW) (>4500 g) and normal birthweight. The neonatal parameters included birthweight percentiles also based on the national birthweight reference [23]: SGA defined as birthweight <10th percentile, very SGA defined as birthweight $<3$ rd percentile, large for gestational age (LGA) defined as birthweight $>90$ th percentile and very LGA defined as birthweight $>97$ th percentile. The information of pregnancy and neonatal outcomes were obtained from electronic medical records. The missing data was perfected by contact with midwives or treating obstetricians.

\section{Statistical analysis}

One-way analysis of variance was performed for continuous data, while Pearson's chi-squared test or Fisher's exact test were applied for categorical data. A post hoc Bonferroni correction was performed for 
multiple comparisons. The association between maternal age and neonatal outcomes was detected by multivariable logistic regression analysis, while the independent effect of maternal age on neonatal outcomes was analyzed by a multiple linear regression.

The multivariable analyses included the following confounders: maternal BMI, parity, infertility cause and duration, insemination method, the type of endometrial preparation, endometrial thickness, the year of treatment and newborn gender. In multivariable models, continuous covariates (maternal BMI, infertility duration, endometrial thickness and the year of treatment) and categorical covariates were indicated in Table 1. Maternal age with 30-34 years was taken as a reference group in multivariable analyses. For the development of IVF techniques over time [24], a sensitivity analysis was performed on treating the year of treatment as a categorical variable. All analyses were conducted with SPSS Statistics (version 21.0) and $P<0.05$ was considered to be statistically significant.

Table 1 Patient treatment and demographic characteristics according to maternal age.

\begin{tabular}{|c|c|c|c|c|c|}
\hline & $\begin{array}{l}<30 \mathrm{y} \\
\mathrm{n}=3586\end{array}$ & $\begin{array}{l}30-34 y \\
n=5461\end{array}$ & $\begin{array}{l}35-39 y \\
n=2861\end{array}$ & $\begin{array}{l}\geq 40 y \\
\mathrm{n}=657\end{array}$ & $P$ value \\
\hline Age & $27.29 \pm 1.63$ & $31.93 \pm 1.40$ & $36.47 \pm 1.34$ & $41.31 \pm 1.53$ & $<0.001^{a}$ \\
\hline Maternal BMI (kg/m2) & $21.21 \pm 2.75$ & $21.45 \pm 2.66$ & $21.69 \pm 2.61$ & $21.95 \pm 2.37$ & $<0.001^{a}$ \\
\hline Infertility cause & & & & & $<0.001^{b}$ \\
\hline Female & $2508(69.9)$ & $3821(70.0)$ & 2001 (69.9) & $449(68.3)$ & \\
\hline Male & $504(14.1)$ & $653(12.0)$ & $284(9.9)$ & $64(9.7)$ & \\
\hline Mixed & $510(14.2)$ & $828(15.2)$ & $494(17.3)$ & $127(19.3)$ & \\
\hline Unexplained & $64(1.8)$ & $159(2.9)$ & $82(2.9)$ & $17(2.6)$ & \\
\hline Parity & & & & & $<0.001^{b}$ \\
\hline 0 & 3489 (97.3) & $5159(94.5)$ & $2478(86.6)$ & $471(71.7)$ & \\
\hline$>0$ & $97(2.7)$ & $302(5.5)$ & $383(13.4)$ & $186(28.3)$ & \\
\hline Infertility duration (years) & $2.53 \pm 1.82$ & $3.29 \pm 2.42$ & $4.11 \pm 3.41$ & $4.70 \pm 4.55$ & $<0.001^{\mathrm{a}}$ \\
\hline FET cycle rank & & & & & $<0.001^{b}$ \\
\hline First & $2332(65.0)$ & $3112(57.0)$ & $1444(50.5)$ & $298(45.4)$ & \\
\hline High order & $1254(35.0)$ & $2349(43.0)$ & $1417(49.5)$ & $359(54.6)$ & \\
\hline Fertilization method & & & & & $<0.001^{b}$ \\
\hline IVF & $2210(61.6)$ & $3425(62.7)$ & $1871(65.4)$ & $414(63.0)$ & \\
\hline ICSI & $990(27.6)$ & $1407(25.8)$ & $762(26.6)$ & $225(34.2)$ & \\
\hline IVF+ICSI & $386(10.8)$ & $629(11.5)$ & $228(8.0)$ & $18(2.7)$ & \\
\hline Number of embryos transferred & & & & & $<0.001^{\mathrm{b}}$ \\
\hline 1 & $555(15.5)$ & $985(18.0)$ & $569(19.9)$ & $145(22.1)$ & \\
\hline$\geq 2$ & $3031(84.5)$ & $4476(82.0)$ & $2292(80.1)$ & $512(77.9)$ & \\
\hline Embryo developmental stage at transfer & & & & & $0.464^{\mathrm{b}}$ \\
\hline Day 3 & $3010(83.9)$ & $4573(83.7)$ & $2415(84.4)$ & $565(86.0)$ & \\
\hline Day $5 / 6$ & $576(16.1)$ & $888(16.3)$ & $446(15.6)$ & $92(14.0)$ & \\
\hline FET endometrial preparation & & & & & $<0.001^{b}$ \\
\hline Natural cycle & $737(20.6)$ & $1338(24.5)$ & $750(26.2)$ & $176(26.8)$ & \\
\hline Artificial cycle & $2849(79.4)$ & $4123(75.5)$ & $2111(73.8)$ & $481(73.2)$ & \\
\hline Endometrial thickness (mm) & & & & & $<0.001^{b}$ \\
\hline$<8$ & $232(6.5)$ & $399(7.3)$ & $270(9.4)$ & $83(12.6)$ & \\
\hline $8-11$ & $1958(54.6)$ & 3067 (56.2) & $1610(56.3)$ & $369(56.2)$ & \\
\hline$>11$ & $1396(38.9)$ & 1995 (36.5) & $981(34.3)$ & $205(31.2)$ & \\
\hline Year of treatment & & & & & $<0.001^{b}$ \\
\hline $2010-2012$ & $276(7.7)$ & $465(8.5)$ & $218(7.6)$ & $33(5.0)$ & \\
\hline $2013-2015$ & $1693(47.2)$ & $2561(46.9)$ & $1219(42.6)$ & $250(38.1)$ & \\
\hline $2016-2017$ & $1617(45.1)$ & $2435(44.6)$ & $1424(49.8)$ & $375(56.9)$ & \\
\hline
\end{tabular}


Data are mean \pm SD or $n(\%)$.

aOne-way ANOVA.

bPearson chi-square test.

\section{Results}

The final dataset included 12565 women who fulfilled the inclusion criteria, with no loss to follow-up. Baseline demographic and cycle characteristics are presented in Table 1. Comparison between the four groups revealed significant difference for maternal BMI, infertility cause, parity, infertility duration, FET cycle rank, fertilization method, the number of embryo transferred, FET endometrial preparation, endometrial thickness and year of treatment. Embryo developmental stage at transfer did not differ significantly among maternal age categories.

Neonatal outcomes stratified by maternal age are listed in Table 2. There was no significant difference on mean birthweight and gestation-adjusted Z-scores varied significantly according to maternal age categories. The group with 30-34 years old had the highest birthweight and Z-scores $(3355.8 \pm 483.3 \mathrm{~g}$, $0.38 \pm 1.03)$. A modest decrease decline of birthweight was observed combined with the increased age when patients age over 30 years old, and group over 40 years old had the lowest birthweight values as $3321.6 \pm 503.9 \mathrm{~g}$. Additionally, no significant differences were found between any two groups by Post hoc analysis on birthweight and Z-scores. The highest proportions of LBW (4.1\%) and HBW (1.2\%) were found in group over 40 years old, but no difference was observed among four groups. In addition, this older group had the highest proportion on PTB (5.9\%) and very PTB $(0.9 \%)$, and Pearson chi-square test showed significant difference on very PTB among maternal age categories. Interestingly, the group with 35-39 years old had the highest very LBW $(0.6 \%)$, while the group with $30-34$ years old had the lowest SGA (2.7\%). Furthermore, there was no difference in very LGA, LGA, very SGA, and newborn gender between groups. 
Table 2

Neonatal outcomes of live born singletons by maternal age.

\begin{tabular}{|c|c|c|c|c|c|}
\hline & $<30 y$ & $30-34 y$ & & & $\begin{array}{l}\mathrm{P} \\
\text { value }\end{array}$ \\
\hline & $n=3586$ & $n=5461$ & $\mathrm{n}=2861$ & $n=657$ & \\
\hline Gestational age & & & & & \\
\hline$\geq 37$ weeks & $\begin{array}{l}3367 \\
(93.9)\end{array}$ & $\begin{array}{l}5117 \\
(93.7)\end{array}$ & $\begin{array}{l}2694 \\
(94.2)\end{array}$ & $612(93.2)$ & $0.254^{b}$ \\
\hline preterm birth (<37 weeks) & $198(5.5)$ & $316(5.8)$ & $143(5.0)$ & $39(5.9)$ & $0.077^{b}$ \\
\hline very preterm birth (<32 weeks) & $21(0.6)$ & $28(0.5)$ & $24(0.8)$ & $6(0.9)$ & $0.015^{c}$ \\
\hline Birthweight (g) & $\begin{array}{l}3352.2 \pm \\
485.7\end{array}$ & $\begin{array}{l}3355.8 \pm \\
483.3\end{array}$ & $\begin{array}{l}3334.2 \pm \\
493.6\end{array}$ & $\begin{array}{l}3321.6 \pm \\
503.9\end{array}$ & $0.711^{\mathrm{a}}$ \\
\hline Z-scores & $\begin{array}{l}0.36 \pm \\
1.04\end{array}$ & $\begin{array}{l}0.38 \pm \\
1.03\end{array}$ & $\begin{array}{l}0.35 \pm \\
1.06\end{array}$ & $\begin{array}{l}0.38 \pm \\
1.10\end{array}$ & $0.253^{a}$ \\
\hline Very low birthweight $(<1500 \mathrm{~g})$ & $12(0.3)$ & $19(0.3)$ & $17(0.6)$ & $2(0.3)$ & $0.030^{c}$ \\
\hline Low birthweight $(<2500 \mathrm{~g})$ & $107(3.0)$ & $181(3.3)$ & $90(3.1)$ & $27(4.1)$ & $0.066^{b}$ \\
\hline High birthweight $(>4500 \mathrm{~g})$ & $27(0.8)$ & $48(0.9)$ & $22(0.8)$ & $8(1.2)$ & $0.145^{c}$ \\
\hline $\begin{array}{l}\text { Very small for gestational age (< } \\
\text { 3rd percentile) }\end{array}$ & $48(1.3)$ & $83(1.5)$ & $35(1.2)$ & $9(1.4)$ & $0.488^{c}$ \\
\hline $\begin{array}{l}\text { Small for gestational age }(<10 \text { th } \\
\text { percentile) }\end{array}$ & $126(3.5)$ & $150(2.7)$ & $100(3.5)$ & $20(3.0)$ & $0.019^{b}$ \\
\hline $\begin{array}{l}\text { Large for gestational age ( }>90 \text { th } \\
\text { percentile) }\end{array}$ & $369(10.3)$ & $583(10.7)$ & $326(11.4)$ & $74(11.3)$ & $0.203^{b}$ \\
\hline $\begin{array}{l}\text { Very large of gestational age (> } \\
97 \text { th percentile) }\end{array}$ & $258(7.2)$ & $354(6.5)$ & $183(6.4)$ & $46(7.0)$ & $0.337^{b}$ \\
\hline Newborn gender & & & & & $0.746^{b}$ \\
\hline Female & $\begin{array}{l}1881 \\
(52.5)\end{array}$ & $\begin{array}{l}2839 \\
(52.0)\end{array}$ & $\begin{array}{l}1522 \\
(53.2)\end{array}$ & $349(53.1)$ & \\
\hline Male & $\begin{array}{l}1705 \\
(47.5)\end{array}$ & $\begin{array}{l}2622 \\
(48.0)\end{array}$ & $\begin{array}{l}1339 \\
(46.8)\end{array}$ & $308(46.9)$ & \\
\hline Data are mean \pm SD or $n(\%)$ & & & & & \\
\hline aOne-way ANOVA. & & & & & \\
\hline bPearson chi-square test. & & & & & \\
\hline cFisher's exact test. & & & & & \\
\hline
\end{tabular}


In multivariate analyses (Table 3), the risk of PTB ( $<37$ weeks) was slightly increased in term singletons originating from the group with 35-39 years old as compared with those from the reference group (aOR $1.23,95 \% \mathrm{Cl}: 1.00-1.51)$. The odds of LBW and HBW for term infants was lower in group over 40 years old as compared with the reference group, not reaching significant difference. Although the analysis of very PTB ( $<32$ weeks), very LBW $(<1500 \mathrm{~g})$ were performed, the number of cases in the two categories was too small to make any meaningful comparisons. It was noteworthy that the risks of SGA and very LGA in term singletons of group under 30 years old was lower than the reference group (aOR $0.77,95 \% \mathrm{Cl}$ : $0.60-0.99$, aOR $0.84,95 \% \mathrm{Cl}: 0.71-1.00)$. 
Table 3

Odds Ratios for gestational age and birth weights by maternal age.

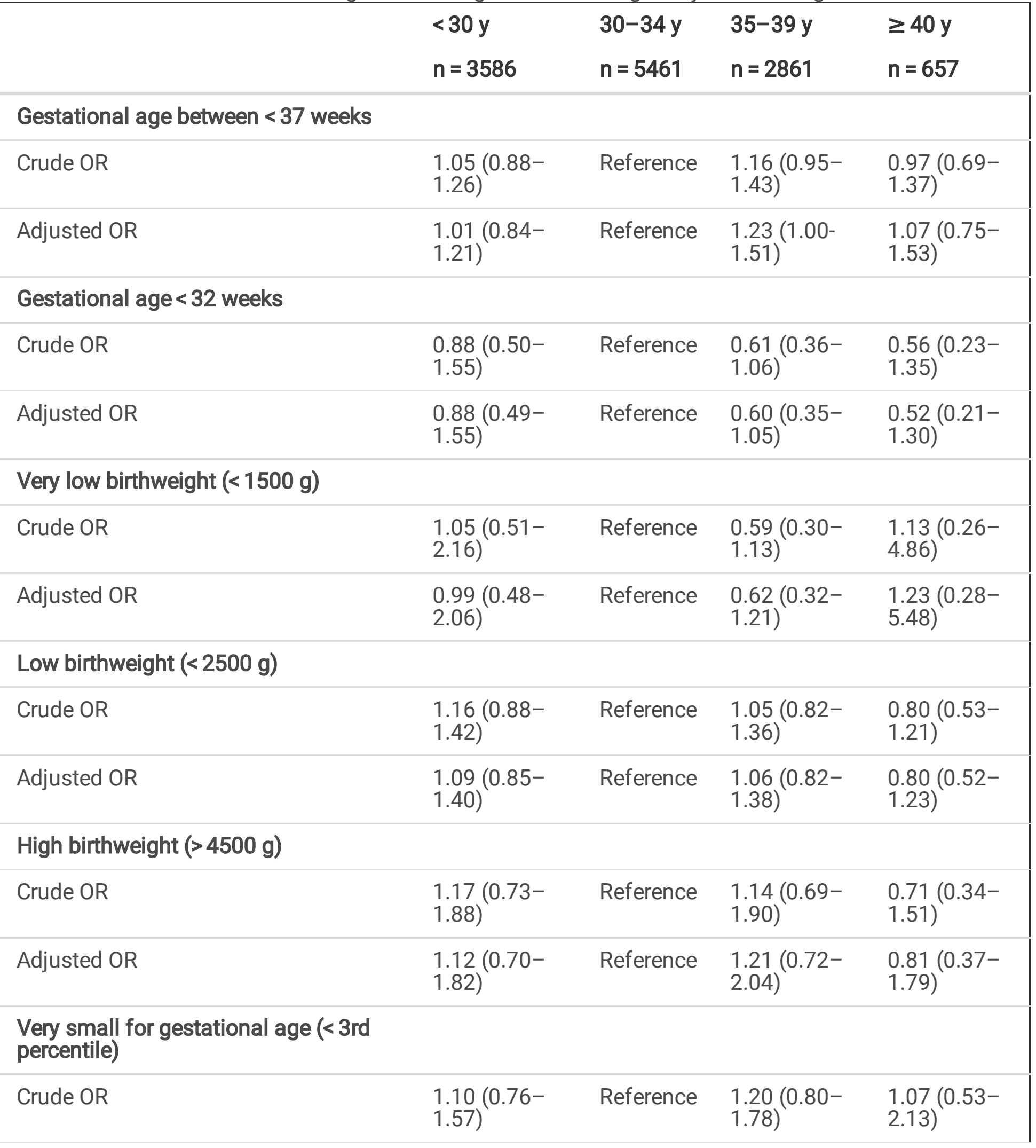

Data are Odds Ratios (OR) with 95\% confidence interval (Cl). Analyses were adjusted for maternal $\mathrm{BMI}$, infertility cause, parity, infertility duration, FET cycle rank, infertility cause, fertilization method, number of embryos transferred, embryo developmental stage at transfer, the type of endometrial preparation, endometrial thickness, year of treatment, and newborn sex. 


\begin{tabular}{|c|c|c|c|c|}
\hline & $<30 y$ & & & $\geq 40 y$ \\
\hline & $n=3586$ & $n=5461$ & $n=2861$ & $n=657$ \\
\hline Adjusted OR & $\begin{array}{l}1.11(0.77- \\
1.61)\end{array}$ & Reference & $\begin{array}{l}1.12(0.74- \\
1.68)\end{array}$ & $\begin{array}{l}0.91(0.44- \\
1.86)\end{array}$ \\
\hline \multicolumn{5}{|c|}{$\begin{array}{l}\text { Small for gestational age ( }<10 \text { th } \\
\text { percentile) }\end{array}$} \\
\hline Crude OR & $\begin{array}{l}0.78(0.61- \\
0.99)\end{array}$ & Reference & $\begin{array}{l}0.78(0.60- \\
1.01)\end{array}$ & $\begin{array}{l}0.89(0.55- \\
1.43)\end{array}$ \\
\hline Adjusted OR & $\begin{array}{l}0.77(0.60- \\
0.99)\end{array}$ & Reference & $\begin{array}{l}0.79(0.61- \\
1.03)\end{array}$ & $\begin{array}{l}0.92(0.56- \\
1.51)\end{array}$ \\
\hline \multicolumn{5}{|c|}{$\begin{array}{l}\text { Large for gestational age (>90th } \\
\text { percentile) }\end{array}$} \\
\hline Crude OR & $\begin{array}{l}1.02(0.89- \\
1.18)\end{array}$ & Reference & $\begin{array}{l}0.92(0.80- \\
1.06)\end{array}$ & $\begin{array}{l}0.93(0.72- \\
1.21)\end{array}$ \\
\hline Adjusted OR & $\begin{array}{l}1.00(0.87- \\
1.15)\end{array}$ & Reference & $\begin{array}{l}0.94(0.81- \\
1.09)\end{array}$ & $\begin{array}{l}0.96(0.73- \\
1.26)\end{array}$ \\
\hline \multicolumn{5}{|c|}{$\begin{array}{l}\text { Very large of gestational age ( }>97 \text { th } \\
\text { percentile) }\end{array}$} \\
\hline Crude OR & $\begin{array}{l}0.89(0.76- \\
1.06)\end{array}$ & Reference & $\begin{array}{l}1.00(0.83- \\
1.20)\end{array}$ & $\begin{array}{l}0.91(0.66- \\
1.26)\end{array}$ \\
\hline Adjusted OR & $\begin{array}{l}0.84(0.71- \\
1.00)\end{array}$ & Reference & $\begin{array}{l}1.07(0.88- \\
1.29)\end{array}$ & $\begin{array}{l}1.02(0.73- \\
1.42)\end{array}$ \\
\hline \multicolumn{5}{|c|}{$\begin{array}{l}\text { Data are Odds Ratios (OR) with } 95 \% \text { confidence interval }(\mathrm{Cl}) \text {. Analyses were adjusted for maternal } \\
\text { BMI, infertility cause, parity, infertility duration, FET cycle rank, infertility cause, fertilization method, } \\
\text { number of embryos transferred, embryo developmental stage at transfer, the type of endometrial } \\
\text { preparation, endometrial thickness, year of treatment, and newborn sex. }\end{array}$} \\
\hline
\end{tabular}

Multiple linear regression analyses were conducted to assess the relationship between maternal age and birthweight (Table 4). Even after correction for a number of potential confounders, no significant correlation was found between maternal age and neonatal birthweight. Moreover, maternal BMI $(P<$ $0.001)$, parity $(P<0.001)$, FET cycle rank $(P<0.001)$, number of embryos transferred $(P=0.029)$, embryo developmental stage at transfer $(P<0.001)$, FET endometrial preparation $(P=0.045)$, endometrial thickness (8-11 mm, $P=0.025 ;>11 \mathrm{~mm}, P=0.002)$, year of treatment $(P<0.001)$, gestational age $(P<$ $0.001)$ and newborn gender $(P<0.001)$ were all independent predictors for birthweight. 
Table 4

Results of multiple regression analysis of singleton birthweight.

\begin{tabular}{|c|c|c|c|c|c|}
\hline & $\begin{array}{l}\text { Unstandardised } \\
\text { coefficients }\end{array}$ & & $\begin{array}{l}\text { Standardised } \\
\text { coefficients }\end{array}$ & $\mathrm{t}$ & $\begin{array}{l}\mathrm{P} \\
\text { value }\end{array}$ \\
\hline & B & $\begin{array}{l}\text { Std. } \\
\text { error }\end{array}$ & Beta & & \\
\hline (Constant) & -3887.276 & 100.441 & & -38.702 & $\dot{0} 001$ \\
\hline \multicolumn{6}{|l|}{ Maternal age } \\
\hline$<30$ & -1.444 & 8.734 & -0.001 & -0.165 & 0.869 \\
\hline \multicolumn{6}{|l|}{ 30-34 (Reference) } \\
\hline $35-39$ & -5.811 & 9.443 & -0.005 & -0.615 & 0.538 \\
\hline$\geq 40$ & 1.148 & 17.128 & 0.001 & 0.067 & 0.947 \\
\hline Maternal BMI (kg/m2) & 25.116 & 1.358 & 0.137 & 18.498 & $\dot{0.001}$ \\
\hline Parity, high order (versus 0) & 61.981 & 13.873 & 0.034 & 4.468 & $\dot{0.001}$ \\
\hline Infertility duration (years) & 0.950 & 1.357 & 0.005 & 0.700 & 0.484 \\
\hline $\begin{array}{l}\text { FET cycle rank, High order (versus } \\
\text { First) }\end{array}$ & 26.077 & 7.482 & 0.026 & 3.485 & $\dot{0} 001$ \\
\hline \multicolumn{6}{|l|}{ Infertility cause } \\
\hline \multicolumn{6}{|l|}{ Female (reference) } \\
\hline Male & -11.298 & 12.933 & -0.008 & -0.874 & 0.382 \\
\hline Mixed & -8.553 & 10.717 & -0.006 & -0.798 & 0.425 \\
\hline Unexplained & 9.061 & 23.193 & 0.003 & 0.391 & 0.696 \\
\hline \multicolumn{6}{|l|}{ Fertilization method } \\
\hline \multicolumn{6}{|l|}{ IVF (reference) } \\
\hline ICSI & -16.795 & 9.827 & -0.015 & -1.709 & 0.087 \\
\hline VF + ICSI & 1.821 & 12.534 & 0.001 & .145 & 0.885 \\
\hline $\begin{array}{l}\text { Number of embryos transferred, } \\
\geq 2 \text { (versus } 1 \text { ) }\end{array}$ & 22.917 & 10.495 & 0.018 & 2.184 & 0.029 \\
\hline $\begin{array}{l}\text { Embryo developmental stage at } \\
\text { transfer, Day } 5 / 6 \text { (versus Day } 3 \text { ) }\end{array}$ & 72.513 & 11.102 & 0.054 & 6.532 & $\dot{L}_{0.001}$ \\
\hline
\end{tabular}




\begin{tabular}{|llllll|}
\hline & $\begin{array}{l}\text { Unstandardised } \\
\text { coefficients }\end{array}$ & & $\begin{array}{l}\text { Standardised } \\
\text { coefficients }\end{array}$ & t & $\begin{array}{l}\text { v } \\
\text { value }\end{array}$ \\
\hline $\begin{array}{l}\text { FET endometrial preparation, } \\
\text { Artificial cycle (versus Natural } \\
\text { cycle) }\end{array}$ & -17.009 & 8.471 & -0.015 & -2.008 & 0.045 \\
\hline Endometrial thickness (mm) & & & & & \\
\hline$<8$ (reference) & & & & & \\
\hline $8-11$ & 30.651 & 13.712 & 0.031 & 2.235 & 0.025 \\
\hline$>11$ & 44.592 & 14.187 & 0.044 & 3.143 & 0.002 \\
\hline Year of treatment & & & & & \\
\hline $2010-2012$ (reference) & & & & & \\
\hline $2013-2015$ & -62.026 & 13.895 & -0.063 & -4.464 & $<$ \\
\hline $2016-2017$ & -78.956 & 14.033 & -0.081 & -5.626 & $<$ \\
\hline Gestational age (week) & 179.131 & 2.422 & 0.549 & 73.970 & $<$ \\
\hline $\begin{array}{l}\text { Newborn gender, female (versus } \\
\text { male) }\end{array}$ & -137.087 & 7.179 & -0.140 & -19.097 & $<$ \\
\hline
\end{tabular}

\section{Discussion}

Recent years, much attention has been paid to the impact of maternal age on ART success rates, and several studies have revealed that a high maternal age (over 40 years old) has a negative effect on pregnancy outcomes $[11,13]$. However, our study showed that no significant association existed between maternal age and neonatal birthweight. Furthermore, linear regression indicated that maternal age was not an independent predictor of birthweight.

Four studies, as we know, have been interested in the potential relationship between maternal age and neonatal birthweight. Wennberg et al. investigated maternal age influencing adverse maternal and neonatal outcomes following ART treatment, suggesting that the risk of LBW and very LBW was significantly higher in ART than in spontaneous conception (SC) singletons in all ages up to maternal age 40 years (LBW: aORs 1.44-2.35; VLBW: aORs 1.67-3.44). Additionally, when the analysis was restricted to maternal age $>35$ years, an increased risk of LBW existed for SC pregnancies, but not for ART pregnancies [11]. Secondly, Moaddab et al. found that maternal age did not predict newborns' birthweight in pregnancies with maternal age grouping as $<40,40-44,45-49, \geq 50$ years old [12]. However, maternal age grouping < 40 years old per se have an inadequate analysis on birthweight and miss important information. Many studies have set up more detailed groups with maternal age under 40 years old to 
assess the influence of maternal age on neonatal outcomes and gained the more credible results $[13,14]$. Another study reported that the risk of LBW was increased only at maternal ages over 40 years old (6 percentage points, $95 \% \mathrm{Cl}: 0.2,12$ ) with medically assisted reproduction (MAR) [13]. However, a limited number of confounders were included in the study, and the effect of different kinds of MAR treatments could not be reliably distinguished, which included less invasive treatments that were less strongly associated with adverse birth outcomes [25]. A recent study based on 4,958 infertile women using a freeze-all strategy observed that maternal age grouping was not related with increased risks of LBW, very LBW, preterm LBW and macrosomia [14]. Yet it only focused on women undergoing their first embryo transfer cycle and ignored the differences in fetus number, and endometrial preparation methods between groups.

Our study aimed to improve on the flaws of abovementioned studies, and focused on the exact role of maternal age in the neonatal birthweight. The current study based on more than 12500 singleton newborns born after FET cycles, demonstrated that maternal age itself had no impact on singleton birthweight. The reason why no significant correlation existed between maternal age and birthweight in our study is likely complex. It is generally known that with aging comes a reduction in ovarian function, resulting in the decrease of ovarian response to ovulation promoting drugs and the low number of oocytes retrieved [26]. Additionally, the decreased quality of oocytes [27, 28], abnormal endometrial function and degeneration of multiple organs function will appear in women with advanced maternal age $[22,29]$. All the above mentioned factors would affect the development of embryo and cause adverse effects on the newborn, leading to LBW. However, with the popularization of education, many women tend to choose late marriage and late childbearing and enjoy a simple single life before marriage. In this kind of life, they are less stressed and have more opportunities to get in touch with life freedom than the women who are married and have children. Meanwhile, these knowledge women have better living habits, physical quality and economic conditions, thus having a better choice on ART treatment [11]. Aging leads to an irreversible decline in fertility, forcing older women to pay more attention on pregnancy and to seek medical help more actively than the young. In addition, the spouse's income also increase with age to guarantee maternity. Most importantly, the development of ART has well fulfilled the reproductive needs of women with different ages to improve the quality of newborns.

In this study, results from multiple linear regression analysis indicated that maternal BMI, embryo developmental stage at transfer, parity, number of embryos transferred, FET endometrial preparation, endometrial thickness, gestational age and newborn gender, were the independent predictors for neonatal birthweight, which was consistent with previous results [22, 30, 31]. Z-scores were calculated and compared across the four groups in order to reduce bias caused by newborn gender and gestational age, and no significant difference on Z-scores was found among different maternal age groups. In addition, there were significant differences between the maternal age groups in baseline and cycle characteristics including infertility duration, infertility cause and fertilization method. However, these confounders had no impact on neonatal birthweight based on the linear regression model. 
There are limitations in our study. The biggest one is its retrospective design, so we strictly checked the database with strict criteria. Secondly, due to personal privacy restrictions, we were unable to obtain the education and economic background of patients. However, The large number of singleton live births from a single centre can assure the practice consistency, which is the main strength of the current study. Additionally, aside from the change of culture medium types, all other laboratory conditions and protocols remained invariant throughout the study period. Further, maternal age was recorded according to the identification card, and endometrial thickness was measured by the same trained sonographers, reducing the recorder variability. Importantly, a number of potential confounders were included in our study, which may minimize their impact on the findings.

\section{Conclusions}

This study expands the current knowledge about association between maternal age and IVF/ICSI outcomes, especially indicated that maternal age was not associated with mean birthweight and Zscores. This important finding should be adequately applied for women over 40 years old prior to FET and strengthen their confidence. A large prospective study, of course, are needed to verify our findings in future.

\section{Abbreviations}

ART assisted reproductive technology

FET frozen embryo transfer

BMI body mass index

IVF in vitro fertilization

ICSI intracytoplasmic sperm injection

PTB preterm birth

LBW low birthweight

SGA small for gestational age

GA gestational age

HBW high birthweight

LGA large for gestational age 
OR odds ratios

Cl confidence interval

SC spontaneous conception

MAR medically assisted reproduction

\section{Declarations}

\section{Ethics approval and consent to participate}

This study was approved by the Institutional Review Board of the Ninth People's Hospital of Shanghai Jiao Tong University School of Medicine. Trial registration number was not applicable.

\section{Consent for publication}

Not applicable.

\section{Availability of data and materials}

The data that support the findings of this study are available from the Ninth People's Hospital of Shanghai Jiao Tong University School of Medicine, but restrictions apply to the availability of these data, which were used under guidelines for the current study, and so are not publicly available.

\section{Competing Interest}

The authors have no conflicts of interest to declare.

\section{Funding}

the National Natural Science Foundation of China $(81774352,81573755,81503604,81703874)$.

\section{Authors' contributions}

C.Q.Y and Y.P.K. conceived and designed this study. Z.X.N. and S.S. contributed to data acquisition, analysis and interpretation and drafted the manuscript. W.C., J.Y., D.Z, D.Y.Z., and Z.L.C. were responsible for the collection of data. All authors interpreted the data.

\section{Acknowledgements}

The authors thank the nurses and laboratory staff of the Department of Assisted Reproduction for their contribution to this work. Moreover, the authors thank the infertile couples who participated in this study. 


\section{References}

1. Nygren KG, Andersen AN: Assisted reproductive technology in Europe, 1997. Results generated from European registers by ESHRE. European IVF-Monitoring Programme EIM), for the European Society of Human Reproduction and Embryology (ESHRE). Human reproduction (Oxford, England) 2001, 16(2):384-391.

2. De Geyter C, Calhaz-Jorge C, Kupka MS, Wyns C, Mocanu E, Motrenko T, Scaravelli G, Smeenk J, Vidakovic S, Goossens V: ART in Europe, 2015: results generated from European registries by ESHRE. 2020, 2020(1):hoz038.

3. Berntsen S, Soderstrom-Anttila V, Wennerholm UB, Laivuori H, Loft A, Oldereid NB, Romundstad LB, Bergh C, Pinborg A: The health of children conceived by ART: 'the chicken or the egg?'. Human reproduction update 2019, 25(2):137-158.

4. Kawwass JF, Badell ML: Maternal and Fetal Risk Associated With Assisted Reproductive Technology. Obstetrics and gynecology 2018, 132(3):763-772.

5. Budak A, Pinheiro RL, Areia AL, Mota Pinto A, Donato H: Advanced Maternal Age: Adverse Outcomes of Pregnancy, A Meta-Analysis. Journal of obstetrics and gynaecology : the journal of the Institute of Obstetrics and Gynaecology 2019, 32(3):219-226.

6. Leader J, Bajwa A, Lanes A, Hua X, Rennicks White R, Rybak N, Walker M: The Effect of Very Advanced Maternal Age on Maternal and Neonatal Outcomes: A Systematic Review. Journal of obstetrics and gynaecology Canada : JOGC = Journal d'obstetrique et gynecologie du Canada : JOGC 2018, 40(9):1208-1218.

7. Lean SC, Derricott H, Jones RL, Heazell AEP: Advanced maternal age and adverse pregnancy outcomes: A systematic review and meta-analysis. PloS one 2017, 12(10):e0186287.

8. Wu Y, Chen Y, Shen M, Guo Y, Wen SW, Lanes A, White RR, Adanlawo A, Walker M, Hua X: Adverse maternal and neonatal outcomes among singleton pregnancies in women of very advanced maternal age: a retrospective cohort study. BMC pregnancy and childbirth 2019, 19(1):3.

9. Koshida S, Arima H, Fujii T, Ito Y, Murakami T, Takahashi K: Impact of advanced maternal age on adverse infant outcomes: A Japanese population-based study. European journal of obstetrics, gynecology, and reproductive biology 2019, 242:178-181.

10. Luke B, Brown MB: Elevated risks of pregnancy complications and adverse outcomes with increasing maternal age. Human reproduction (Oxford, England) 2007, 22(5):1264-1272.

11. Wennberg AL, Opdahl S, Bergh C, Aaris Henningsen AK, Gissler M, Romundstad LB, Pinborg A, Tiitinen A, Skjaerven R, Wennerholm UB: Effect of maternal age on maternal and neonatal outcomes after assisted reproductive technology. Fertility and sterility 2016, 106(5):1142-1149.e1114.

12. Moaddab A, Chervenak FA, McCullough LB, Sangi-Haghpeykar H, Shamshirsaz AA, Schutt A, Arian SE, Fox KA, Dildy GA, Shamshirsaz AA: Effect of advanced maternal age on maternal and neonatal 
outcomes in assisted reproductive technology pregnancies. European journal of obstetrics, gynecology, and reproductive biology 2017, 216:178-183.

13. Barbuscia A, Martikainen P, Myrskyla M, Remes H, Somigliana E, Klemetti R, Goisis A: Maternal age and risk of low birth weight and premature birth in children conceived through medically assisted reproduction. Evidence from Finnish population registers. Human reproduction (Oxford, England) 2020, 35(1):212-220.

14. Lin J, Huang J, Zhu Q, Kuang Y, Cai R, Wang Y: Effect of Maternal Age on Pregnancy or Neonatal Outcomes Among 4,958 Infertile Women Using a Freeze-All Strategy. Frontiers in medicine 2019, $6: 316$.

15. Pereira N, Elias RT, Christos PJ, Petrini AC, Hancock K, Lekovich JP, Rosenwaks Z: Supraphysiologic estradiol is an independent predictor of low birth weight in full-term singletons born after fresh embryo transfer. Human reproduction (Oxford, England) 2017, 32(7):1410-1417.

16. Imudia AN, Awonuga AO, Doyle JO, Kaimal AJ, Wright DL, Toth TL, Styer AK: Peak serum estradiol level during controlled ovarian hyperstimulation is associated with increased risk of small for gestational age and preeclampsia in singleton pregnancies after in vitro fertilization. Fertility and sterility 2012, 97(6):1374-1379.

17. Jarvela IY, Pelkonen S, Uimari O, Makikallio K, Puukka K, Ruokonen A, Tekay A, Martikainen H: Controlled ovarian hyperstimulation leads to high progesterone and estradiol levels during early pregnancy. Human reproduction (Oxford, England) 2014, 29(11):2393-2401.

18. Kuang Y, Chen Q, Hong Q, Lyu Q, Ai A, Fu Y, Shoham Z: Double stimulations during the follicular and luteal phases of poor responders in IVF/ICSI programmes (Shanghai protocol). Reproductive biomedicine online 2014, 29(6):684-691.

19. Kuang Y, Chen Q, Fu Y, Wang Y, Hong Q, Lyu Q, Ai A, Shoham Z: Medroxyprogesterone acetate is an effective oral alternative for preventing premature luteinizing hormone surges in women undergoing controlled ovarian hyperstimulation for in vitro fertilization. Fertility and sterility $2015,104(1): 62-$ 70.e63.

20. Du T, Chen H, Fu R, Chen Q, Wang Y, Mol BW, Kuang Y, Lyu Q: Comparison of ectopic pregnancy risk among transfers of embryos vitrified on day 3, day 5, and day 6 . Fertility and sterility 2017 , 108(1):108-116.e101.

21. Nelissen EC, Van Montfoort AP, Coonen E, Derhaag JG, Geraedts JP, Smits LJ, Land JA, Evers JL, Dumoulin JC: Further evidence that culture media affect perinatal outcome: findings after transfer of fresh and cryopreserved embryos. Human reproduction (Oxford, England) 2012, 27(7):1966-1976.

22. Zhang J, Liu H, Mao X, Chen Q, Si J, Fan Y, Xiao Y, Wang Y, Kuang Y: Effect of endometrial thickness on birthweight in frozen embryo transfer cycles: an analysis including 6181 singleton newborns. Human reproduction (Oxford, England) 2019, 34(9):1707-1715.

23. Dai L, Deng C, Li Y, Zhu J, Mu Y, Deng Y, Mao M, Wang Y, Li Q, Ma S et al: Birth weight reference percentiles for Chinese. PloS one 2014, 9(8):e104779. 
24. Castillo CM, Horne G, Fitzgerald CT, Johnstone ED, Brison DR, Roberts SA: The impact of IVF on birthweight from 1991 to 2015: a cross-sectional study. Human reproduction (Oxford, England) 2019, 34(5):920-931.

25. De Geyter C, Calhaz-Jorge C, Kupka MS, Wyns C, Mocanu E, Motrenko T, Scaravelli G, Smeenk J, Vidakovic S, Goossens V: ART in Europe, 2014: results generated from European registries by ESHRE: The European IVF-monitoring Consortium (EIM) for the European Society of Human Reproduction and Embryology (ESHRE). Human reproduction (Oxford, England) 2018, 33(9):1586-1601.

26. Yang X, Zhang J, Wu J, Huang J, Chen Q, Lu X, Lyu Q, Kuang Y, Wang Y: Association between the number of oocytes retrieved and neonatal outcomes after freeze-all IVF cycles. Human reproduction (Oxford, England) 2019, 34(10):1937-1947.

27. Pacella L, Zander-Fox DL, Armstrong DT, Lane M: Women with reduced ovarian reserve or advanced maternal age have an altered follicular environment. Fertility and sterility 2012, 98(4):986-994.e981982.

28. Pella R, Suarez-Cunza S, Orihuela P, Escudero F, Perez Y, Garcia M, Zorrilla I, Berrio P, Romero S: Oxidative balance in follicular fluid of ART patients of advanced maternal age and blastocyst formation. JBRA assisted reproduction 2020.

29. Gibson DA, Simitsidellis I, Kelepouri O, Critchley HOD, Saunders PTK: Dehydroepiandrosterone enhances decidualization in women of advanced reproductive age. Fertility and sterility 2018, 109(4):728-734.e722.

30. Zhang J, Wang Y, Liu H, Mao X, Chen Q, Fan Y, Xiao Y, Kuang Y: Effect of in vitro culture period on birth weight after vitrified-warmed transfer cycles: analysis of 4,201 singleton newborns. Fertility and sterility 2019, 111(1):97-104.

31. J Z, H L, X M, Q C, Y F, Y X, Y W, Y K: Effect of body mass index on pregnancy outcomes in a freeze-all policy: an analysis of 22,043 first autologous frozen-thawed embryo transfer cycles in China. BMC medicine $2019,17(1): 114$. 